\title{
Time series analysis of interrupted long-term data set (1961-1991) of zooplankton abundance in Gulf of Maine (northern Atlantic, USA)
}

\author{
Priscilla LICANDRO ${ }^{\mathrm{a} * \$}$, Alessandra CONVERSI ${ }^{\mathrm{b}}$, Frédéric IBANEZ ${ }^{\mathrm{a}}$, Jack JOSSI $^{\mathrm{c}}$ \\ ${ }^{a}$ Laboratoire d'océanographie biologique et écologie du plancton marin, ESA 7076, BP 28, \\ 06230 Villefranche-sur-mer, France \\ ${ }^{\mathrm{b}}$ Marine Sciences Research Center, State University of New York at Stony Brook, Stony Brook, \\ NY 11794-5000, USA \\ c US Department of Commerce - NOAA, Narragansett Laboratory, Narragansett, RI 02882, USA
}

\begin{abstract}
The main interannual and seasonal signals have been extracted from a multi-decadal data set of zooplankton collected with the Continuous Plankton Recorder in the Gulf of Maine, from January 1961 to December 1991. The monthly abundances of seven species or genera of copepods representing the dominant biomass in the area were considered. The presence of a large consecutive gap (35 months) prevented the use of statistical methods for the prediction of missing data. The eigen-vector filtering (EVF) method was then used on the original time series, while retaining the missing values. For each zooplankton taxon, two principal modes of variability $\left(F_{1}\right.$ and $\left.F_{2}\right)$ were extracted, representing the interannual and seasonal variations, respectively. Results of EVF allowed the classification of the different genera or species, according to their main type of variability, into taxa 'interannually dominated' $(C$. finmarchicus, Metridia lucens, Oithona spp.), 'seasonally dominated' (Centropages typicus), and taxa characterized by both 'interannual and seasonal variation' (Pseudocalanus spp., Temora longicornis, Acartia spp.). A comparison between the interannual trends of 'interannually dominated species' and sea surface temperature (SST) indicated that all the species were more or less correlated with this important environmental factor. In particular, a strong negative correlation was found between $C$. finmarchicus and SST at a lag of about 0 months, showing that lower values of SST correspond to higher abundances of Calanus finmarchicus at this latitude. (C) 2001 Ifremer/CNRS/IRD/Éditions scientifiques et médicales Elsevier SAS
\end{abstract}

Résumé - Analyse de séries temporelles à long terme (1961-1991) interrompues sur le zooplancton du golfe du Maine (Atlantique Nord). La variabilité temporelle d'une série zooplanctonique a été estimée dans le golfe du Maine (de janvier 1961 à décembre 1991). Les prélèvements ont été réalisés par l'échantillonneur de type CPR (Continuous Plankton Recorder). Les données représentent l'abondance mensuelle moyenne de sept espèces de copépodes, ou catégories, lesquelles correspondent à la plus forte biomasse planctonique du golfe. Une importante lacune dans les enregistrements (35 mois consécutifs sans observations) dénie la possibilité de prédire statistiquement ces données manquantes. C'est pourquoi la méthode de décomposition des séries correspondant au filtrage par les vecteurs propres a été utilisée en conservant les données manquantes. Par la méthode de filtration des vecteurs propres, pour chaque taxon, deux séries $F_{1}$ et $F_{2}$ ont été décelées qui correspondent respectivement à deux échelles de variations, interannuelle et saisonnière. À partir de ces évolutions, une classification des taxons a été obtenue: Calanus finmarchicus, Metridia lucens, Oithona spp. sont principalement marqués par des phénomènes interannuels; Centropages typicus au contraire ne répond qu'à l'échelle saisonnière. Enfin Pseudocalanus spp., Temora longicornis,

*Correspondence and reprints.

E-mail address: licandro@alpha.szn.it (P. Licandro).

$\S$ Present address: Stagione Zoologica Anton Dohrn, Villa Comunale, 80121 Napoli, Italy.

(C) 2001 Ifremer/CNRS/IRD/Éditions scientifiques et médicales Elsevier SAS. Tous droits réservés

S0399178401011690/FLA 
Acartia spp. réagissent aux deux échelles de variation $F_{1}$ et $F_{2}$. Une corrélation a été trouvée entre la tendance générale $F_{1}$ des espèces à dominance interannuelle et la température de surface de la mer. En particulier une corrélation négative très forte apparaît entre $C$. finmarchicus et la température de surface de la mer, sans prendre en compte un décalage temporel ce qui signifie qu'à cette latitude, ce copépode est d'autant plus abondant que les eaux sont froides. (C) 2001 Ifremer/CNRS/IRD/Éditions scientifiques et médicales Elsevier SAS

\section{Calanus finmarchicus / Gulf of Maine / missing data / time series analysis / zooplankton}

\section{Calanus finmarchicus / golfe du Maine / données manquantes / séries temporelles / zooplancton}

\section{INTRODUCTION}

The Gulf of Maine is an area of intense productivity Sherman et al_ 1988) Near the coast, hydrography is mainly influenced by tidal currents, while in the central part of this region circulation is due to a large cyclonic gyre that tends to be stronger in the spring Bigelow 1927; Bumpus and Lauzier, 1965). Tidal mixing and upwelling from the Jordan basin has implications for primary and secondary production in the western part of the Gulf of Maine (Townsend et al. 1987).

Bigelow (1926) first described the zooplankton community of the Gulf of Maine. However, systematic monitoring programs started quite later in the 1960s with the Continuous Plankton Recorder (CPR) (Hardy, 1939) survey, and in the 1970s with the Marine Resources Monitoring, Assessment and Prediction (MARMAP) program Sherman, 1980) These two programs contributed to identifying about 390 zooplanktonic taxa over the continental shelf. Among these, twelve copepods account for $85 \%$ of the total biomass. Seventy-five percent of the twelve taxa is due to Calanus finmarchicus, Pseudocalanus spp. and Centropages typicus Sherman et al. 1988)

Within the US GLOBEC program, Georges bank, a region with hydrographic properties related to those of the Gulf of Maine was chosen as a target study area, as one of the most productive in the USA, and both Calanus finmarchicus and Pseudocalanus spp. were selected as target species. The median annual cycles of Calanus finmarchicus, Pseudocalanus spp., Centropages typicus and Metridia lucens on Georges bank over the period 1977-1981 are shown by Sherman et_al_(1987) Meise and O'Reilly (1996) described the large-scale spatial and seasonal patterns of Calanus finmarchicus in the Gulf of Maine and Georges bank over the period 1977 and 1987. The variation in the seasonal cycle of the same species over a 30-year period, and its relationship with the North Atlantic oscillation (NAO) was described by Conversi et al. (2001).

The precious information contained in the Gulf of Maine time series is however difficult to analyze because of several large gaps in data coverage in the first half of the series. Indeed, the analyses so far published on this series Iossi and Goulet, 1993; Sherman et al, 1998) utilize yearly averaged data. The aim of the present study is to characterize, for seven of the most abundant species/ genera of copepods in the Gulf of Maine, the interannual trends, by extracting without simulating missing data or resorting to annual averages. For this reason we have applied the eigen-vector filtering (EVF) method Ihanez and Etienne. 1992) on monthly abundances of Calanus finmarchicus, Pseudocalanus spp., Centropages typicus, Temora longicornis, Acartia spp., Metridia lucens and Oithona spp. This is the first usage of this method on real data with missing values. The comparisons of the principal trends of each taxonomic category permitted us to distinguish species mostly characterized by a seasonal cycle and species with a strong interannual component. The latter were compared with long-term fluctuations of surface water temperature (SST).

\section{MATERIALS AND METHODS}

\subsection{Data}

Zooplankton data were obtained with the Continuous Plankton Recorder sampler (270- $\mu \mathrm{m}$ mesh), in the framework of US CPR program (Jossi and Goulet, 1993), by horizontal tows at $10 \mathrm{~m}$ depth, on transect across the Gulf of Maine (foure 1 ). Sampling was made with monthly frequency from 1961, but during the first part of 


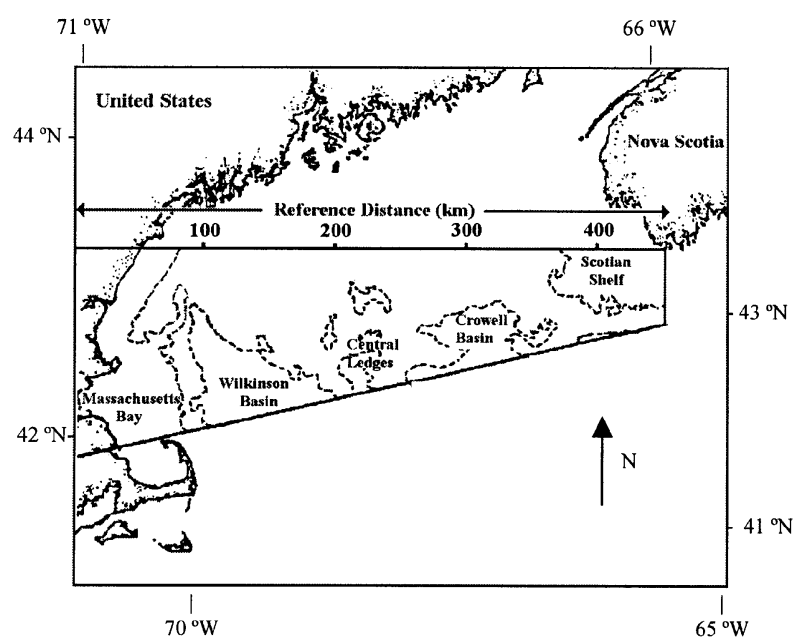

Figure 1. Gulf of Maine. Continuous Plankton Recorder (CPR) sampling from 1961 to 1991 .

the series there were many missing months, and no sampling at all between 1974 and 1977. The sampling protocol, identical for the UK and US collections, is described by Colebrook (1975) and Warner and_Hay 1994 .

For this work, the most abundant species or genera of copepods in the area were studied: Calanus finmarchicus (Copepodites V and VI), Pseudocalanus spp. (CVI), Centropages typicus (unstaged), Temora longicornis (unstaged), Acartia spp. (unstaged), Metridia lucens (CVCVI) and Oithona spp. (CIV-CVI). 'Total copepod' abundance, which is the sum of all 'small' copepods, below $2 \mathrm{~mm}$, was also used. This category includes all the groups mentioned above except for Calanus finmarchicus and Metrida lucens, which are larger (Warner and Hays 1994). The central part of the Gulf of Maine transect (291 km, between 69 $50^{\prime} \mathrm{W}$ and $66^{\circ} 29^{\prime} \mathrm{W}$ ) was chosen because it provided higher temporal coverage than the other parts of the transect, and because it was less influenced by the shelf and estuarine environments. Previous cluster analyses by Jossi and Goulet (unpublished) have shown that the above zooplankton species are homogenous within this spatial section. Zooplankton abundances included day and night samples combined, except for Metridia lucens for which just night records were retained. Log-transformed zooplankton abundances ( $\log _{10}$ ind $\cdot 100 \mathrm{~m}^{-3}$ ) for each month were averaged along this subset of the transect so as to give a unique, pooled spatial value (henceforth called 'Gulf of Maine').
Sea surface temperature (SST) for the Gulf of Maine region was derived from the Comprehensive OceanAtmosphere Data Set (COADS).

\subsection{Numerical Analyses}

\subsubsection{Biological variables}

\subsubsection{Step 1. Zooplankton data set: compression of the series to avoid missing values}

The zooplankton data set was composed of monthly abundances during the period 1961-1991 (372 total observations) for the eight descriptors (seven taxonomic groups and total copepods), with 157 missing months, corresponding to $42 \%$ of the total values for all the groups except for Acartia spp. and Metridia lucens, which had a greater number of missing values, respectively 43 and $50 \%$. The missing months were distributed mostly in the first part of the series, until the end of the 1970s. For each taxonomic group a new series, with $n^{*}$ observations in it (where $n^{*}=n-$ missing values), was calculated by eliminating the gaps and compressing the series (foure 2).

\subsubsection{Step 2. Extraction of the interannual trends by eigen-vector filtering $(E V F)$}

In this work, 'trend' means the main tendencies of any shape over the decades of the series (e.g. interannual and annual trends).

The eigen-vector filtering (EVF) method (PASSTEC package, Lbanez and Etienne, 1998) proposed by Colebrook (1978) and used in benthic ecology by [banez and Dawvin (1988) and [banez(1991, was utilized in order to extract the main trends in each taxonomic group ffgure 2).

EVF, using principal component analysis (PCA), acts as a weighted moving average. Its main property is the capacity of eliminating all the frequency bands equal or higher than the annual cycle. Compared to other wellknown techniques, eigen-vector filtering has the following advantages: no observations are lost at the boundaries of the series, and no arbitrary choice is required regarding the shape of the trend.

With EVF the following steps are implemented on each variable or series (appendix 1): 


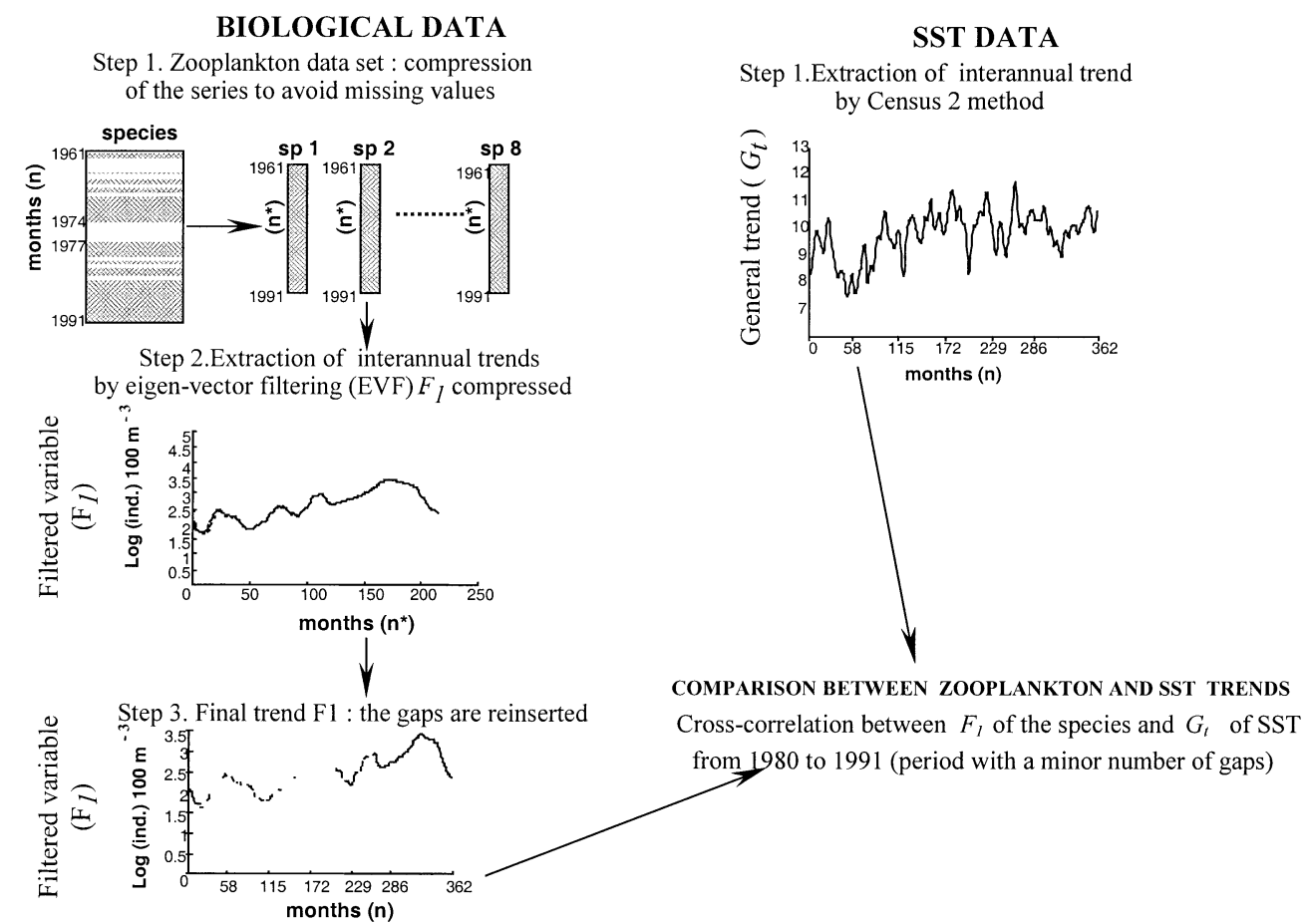

Figure 2. Different steps of the numerical procedure applied to the zooplankton and to the sea surface temperature (SST) data sets in the Gulf of Maine from 1961 to 1991.

- Taking a series $x_{t}, t$ varying between 1 and $N$, shifting in time $x_{t}$, a matrix $\mathrm{X}$ composed of $r$ shifted series is constructed. Each $r$ column of $\mathrm{X}$ has $N-r+1$ values, i.e. the first column has $t=1, \ldots, N-r+1$ values, the second one $t=2, \ldots, N-r+2$ values, ..., the last column (the $r$ th) has $t=r, \ldots, N$ terms. The judicious choice of the number of shifted series, $r$, may be estimated as the lag at which the autocorrelation function of $x_{t}$ goes to zero Takens. 1981. [banez and Etienne, 1992).

- The $r$ eigenvalues and eigenvectors of the $r \times r$ covariance matrix (thus the autocovariance matrix) are extracted and the principal components are computed. The first principal component $\left(C_{1}\right)$ from the autocovariance matrix is associated with the highest variance of the series $x_{t}$. The second principal component, $C_{2}$, corresponds to the main signal after removing $C_{1}$, and so on, with the successive components reflecting less and less variability, indicating by their corresponding row eigenvalues. In most cases (see later), $C_{1}$ will represent the interannual trend of the series and $C_{2}$ the seasonal cycle.

In order to extract the major trends or filtered variables $F_{i}$, the matrix $\hat{X}$ is predicted using the corresponding row eigenvector $U_{i}$ from the autocovariance matrix, and principal component column vector $C_{i}$ :

$$
\hat{\mathrm{X}}_{i}=C_{i} U_{i}^{\prime} \text { where } i=1,2, \ldots, r .
$$

- To build a unique series, $F_{i}$ requires averaging the values of $\hat{X}$. Like in table $\mathrm{X}$, in table $\hat{\mathrm{X}}$ there are $(n-2 r)$ observations which are repeated $r$ times and then the others that are repeated $(r-1),(r-2), \ldots, 1$ time, according to the shift in time done between the columns.

However, Ibanez and_Etienne (1992) showed that $F_{i}$ could be directly estimated as soon as $U_{i}$ is obtained. $F_{i}$ may be calculated by a weighted moving average (WMA) on the original series, $x_{t}$ of order $r-1$, containing $2(r-1)+1$ terms. For each principal axis $F_{i}$ the $i$ th weight is a linear combination of the elements of corresponding eigenvectors $U_{i}$ (see appendix 2 for details).

Although the principal components are independent, the Fs may present significant correlations because of the embedded moving averages. This property is however more ecologically meaningful than complete independence, since for marine species very often the amplitude 
of the seasonal variation is positively linked to the amplitude of the interannual variation Ibanez et al. 1993)

The EVF method was applied to each zooplanktonic series of monthly observations in the Gulf of Maine, after compressing the original data to eliminate missing values. The autocorrelation function for each species went to 0 (with $95 \%$ confidence) at around 7 months. Thus $r$ was chosen for all species as equal to 7 , considering that it gives a weighted moving average of thirteen successive observations, which is most appropriate when dealing with planktonic species since they all have some degree of autocorrelation at the annual scale. Then the major trends of the seven taxonomic groups and of the total copepods were extracted.

Harmonic analysis Gendall. 1976:_Legendre and Le gendre. 1998) was performed on the filtered variables $F_{1}$ and $F_{2}$ of each taxa calculated during the period May 1982-April 1991 (until December 1990 for Acartia spp.), to verify their periodicities. This part of the time series was chosen because it contained just a few $(<4 \%)$ non-consecutive missing values allowing their estimation by interpolation. The significance of each harmonic was tested according to the associated percentage of variance (Anderson, 1971). Since an accurate test of significance would require the stationary distribution of $F_{1}$ and $F_{2}$, this procedure was carried out only to have an indication of the periodicity of filtered variables.

\subsubsection{Step 3. Reconstruction of the actual $\mathrm{F}_{1}$ and $\mathrm{F}_{2}$ and classification of the trends}

After the extraction of $F_{1}$ and $F_{2}$, the gaps are inserted again in the filtered variables, so that they are restored to original length. Taking into account the order of the weighted moving average, the $r-1$ values before and after each gap are biased, thus for $r=7$, six values are more or less biased at each side of gap. At a point $\mathrm{P}_{1}$ just at the boundary of a gap, the smoothed estimate of $\mathrm{P}$ takes into account seven of its adjacent values and six values on the other side of the gap. These points at the boundaries are the most biased. Then, the first adjacent point of $\mathrm{P}_{1}, \mathrm{P}_{2}$, is estimated from eight adjacent values and five values from the other side of the gap. The next point $\mathrm{P}_{3}$ with nine correct values and four incorrect, etc. Finally, when calculating $\mathrm{P}_{7}$ the estimation is unbiased.

$F_{1}$ and $F_{2}$ can outline three different characteristic situations, considering the difference $(\Delta)$ between the corre-
Table I. Classification of the principal copepods of the Gulf of Maine, on the basis of the results of eigen-vector filtering (EVF). The columns $F_{1}$ and $F_{2}$ indicate the $\%$ of variance (also shown for total copepods) associated to the first two principal components extracted from the autocovariance matrix. The column code indicates three categories of species, having different type of variation: ++0 : species with a strong interannual cycle; ++ : species with dominant seasonal cycle; +++ : species with interannual cycle and not negligible seasonal cycle. $\mathrm{R}_{F 1 \cdot F 2}$ indicate the correlation between $F_{1}$ and $F_{2}$.

\begin{tabular}{|c|c|c|c|c|c|}
\hline $\begin{array}{l}\text { Type of } \\
\text { variation }\end{array}$ & Species & $\begin{array}{c}F_{1} \\
(\%)\end{array}$ & $\begin{array}{c}F_{2} \\
(\%)\end{array}$ & Code & $\mathrm{R}_{F 1 \cdot F 2}$ \\
\hline \multicolumn{6}{|c|}{ a) Interannually dominated } \\
\hline & Calanus finmarchicus & 34 & 21 & ++0 & 0.30 \\
\hline & Metridia lucens & 44 & 18 & ++0 & 0.30 \\
\hline & Oithona spp. & 44 & 18 & ++0 & 0.28 \\
\hline \multicolumn{6}{|c|}{ b) Seasonally dominated } \\
\hline & Centropages typicus & 32 & 31 & ++ & 0.71 \\
\hline \multicolumn{6}{|c|}{ c) Interannual/seasonal species } \\
\hline & Pseudocalanus spp. & 34 & 26 & +++ & 0.49 \\
\hline & Temora longicornis & 30 & 19 & +++ & 0.45 \\
\hline & Acartia spp. & 27 & 20 & +++ & 0.39 \\
\hline & Total copepods & 34 & 26 & +++ & \\
\hline
\end{tabular}

sponding eigenvalues $\lambda_{1}$ and $\lambda_{2}$ Ibanez, 1991: Souprayen et al. 1991: Ibanez et al. 1993):

- when $\Delta$ is very high $\left(\lambda_{1}\right.$ is almost twice $\left.\lambda_{2}\right)$ and the correlation between $F_{1}$ and $F_{2}$ is low, only the year to year variation is important.

- when $\Delta$ is very low (less than $1 / 10$ ) and the correlation between $F_{1}$ and $F_{2}$ is significant, the seasonal variation is dominant in the series.

- when $\Delta$ corresponds to an intermediate value, an interannual trend is certainly present but the seasonal variation is not negligible.

The difference $(\Delta)$ between the eigenvalues $\lambda_{1}$ and $\lambda_{2}$ was calculated for all seven taxonomic groups and it corresponds to the difference between the percentages of variance associated with the filtered variables $F_{1}$ and $F_{2}$. The seven genera or species (total copepods were omitted from this calculation as it was targeted toward genera or species) were classified, following the criteria explained above, into 'interannual', 'seasonal' and 'interannual seasonal' taxa (see table ). As the $\Delta$ average of the seven taxa is 8 , this value was arbitrarily chosen as the threshold separating species with a dominant seasonal variation or an intermediate situation, from species with a dominant interannual trend. The latter were then chosen for comparison with environmental data. 


\subsubsection{Environmental variables}

The Census 2 method Shiskin and Eisenpress. 1957 was used on SST monthly data in order to remove the seasonality and to extract the interannual trend Institum hational de statistique, 1965: Béthowx et al, 1980; Eromentin and Ihanez, 1994. By means of successive moving averages, it displays a series of three components: the interannual trend, called 'general trend' $G_{t}$, the 'annual cycle' $A_{t}$, and the 'random component' $I_{t}$, which represents unusual events (figure 2 ). An important property of this method is that, by construction, the interannual and seasonal components present null values for the coherence function at the seasonal frequency. Census 2, more powerful for the decomposition of time series than the EVF, was chosen because of the regularity (no missing data) of the SST series, a necessary condition which prevented its use on our biological series.

Harmonic analysis was performed on the general trend, $G_{t}$, to compute its periodicity.

\subsubsection{Comparison between biological and environmental variables}

The classification method outlined above permitted distinguishing 'seasonally' and 'interannually' dominated taxa. One can reason that the latter are likely to be more easily influenced by large scale environmental changes. Hence the major trends $\left(F_{1}\right)$ of Calanus finmarchicus, Metridia lucens and Oithona spp. (i.e. the three zooplanktonic group which were classified as interannuallydominated') were compared with the interannual trend of SST $\left(G_{t}\right)$ in order to investigate the relationship between temperature, a proxy for large-scale environmental variations, and zooplankton variations. Taking into consideration the large number of missing values until the end of the $1970 \mathrm{~s}$, a cross-correlation was performed on a subseries of $132 F_{1}$ and $C_{t}$ values, corresponding to the period January 1980-December 1991. The maximum lag chosen for the cross correlation was 30 months, in order to maintain a satisfactory number of degrees of freedom and a good estimation of the correlations coefficients.

\section{RESULTS}

The filtered variables $F_{1}$ and $F_{2}$ for the eight zooplanktonic categories are presented in figure 3 , where the different species are ranked, according to the results of the classification of the trends shown in table . The taxa Calanus finmarchicus, Metridia lucens and Oithona spp. (foure $3 a-d$ ) showed the highest interannual variability, taking into account the high difference between the eigenvalues $\lambda_{1}$ and $\lambda_{2}(\Delta>8 \%)$ and the low correlations between their filtered variables table 1 ). Harmonic analysis on the filtered variables of these taxa for the period 1982-1991 (table I Confirmed that $F_{1}$ represents the interannual component (from 36 to $54 \%$ of variance associated to the $\propto$ period), showing a cycle of 54 months for Metridia and Oithona, while $F_{2}$ always represents the annual trend.

In the Gulf of Maine, $C$. finmarchicus is present year round with peaks between May and July (figure 4d). Considering $F_{1}$, which represented its interannual variability, this species showed from 1961 to 1991 an increasing trend, with about $3.5 \log$ ind $100 \mathrm{~m}^{-3}$ more in 1987 (the year of maximum abundance) compared to 1963 (the lowest year). Because of the great number of missing data in the first part of the series, the interannual cycle of $M$. lucens has been studied over a shorter period, from 1979 to 1991 . Metridia, which is mostly present in autumn (figure 4b), showed a decrease of around $2 \log$ ind $100 \mathrm{~m}^{-3}$ from $1979 / 80$ to 1984 , maintained constant abundance until 1989 and thereafter increased again. The annual cycle of Oithona spp. from monthly averages of 1961-1991 foure 4d) indicates that this copepod is generally less abundant from November to March, starts to increase in April and peaks in August and September. Considering the interannual trend figure 3d), after 1963 Oithona's abundances seemed to diminish, and a cycle of 11 years can be detected from 1979 to 1990.

Of all taxa, Centropages typicus is the only one that presents a dominant seasonal variability. $F_{1}$ and $F_{2}$ for this species, which has maximum abundance from August to November (Ggure 4d), are practically identical (figure 3d) and strongly correlated (table d), while harmonic analysis indicates that both $F_{1}$ and $F_{2}$ of Centropages represent a strong seasonal cycle (table $\mathrm{Cl}$ ). On the other hand, Pseudocalanus, Temora and Acartia show both a strong annual variability and a nonnegligible interannual cycle (intermediate $\Delta$, $R_{F 1 \cdot F 2}>0.35$ in table d). This pattern is also confirmed by the lower variance of $\propto$ period of $F_{1}$ for these taxa (between 16 and $25 \%$ ) with respect to 'interannually dominated species'. Pseudocalanus had two major peaks in 1979 and 1982 (Goure 3f), while from 1982 onwards 

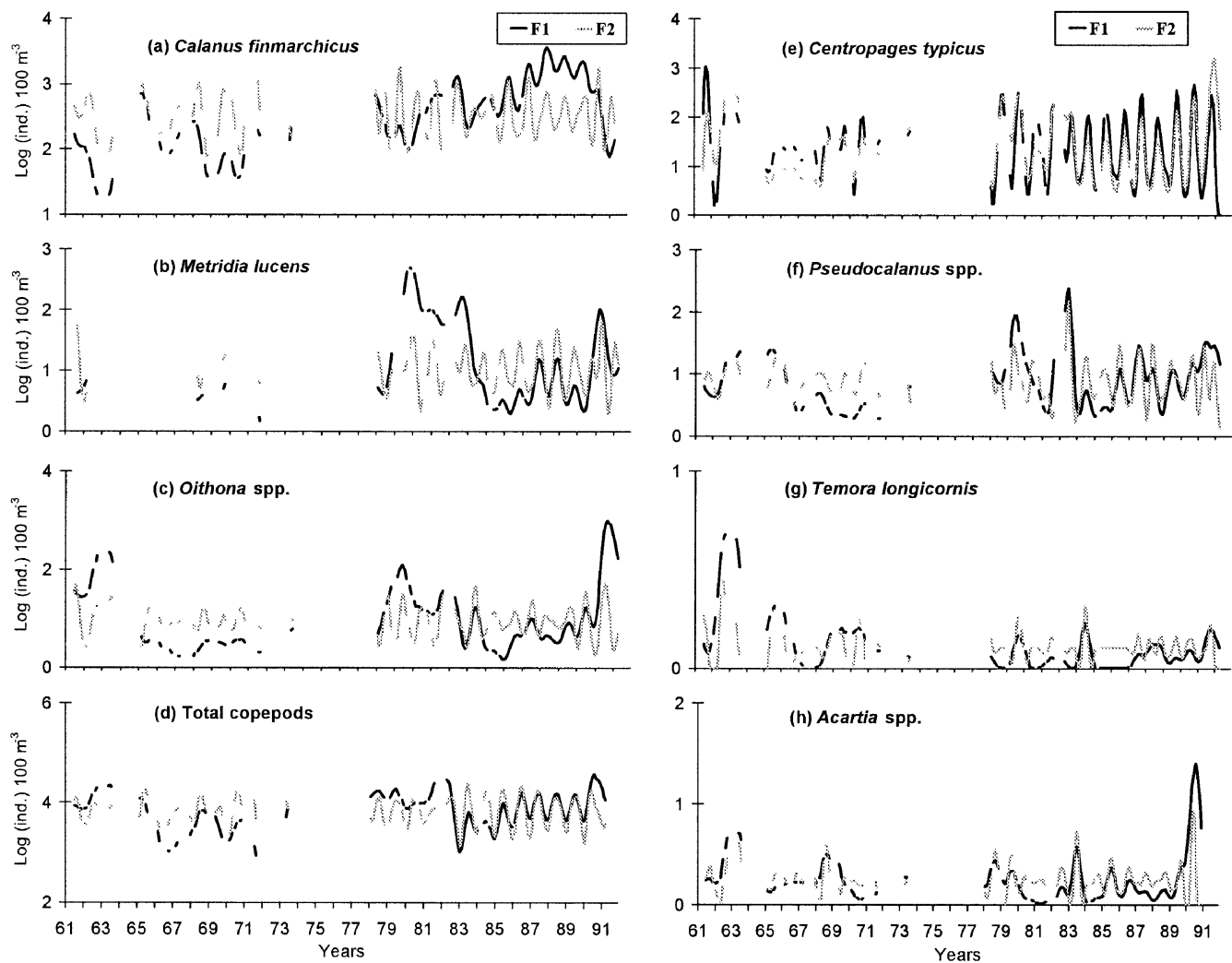

Figure 3. Gulf of Maine, 1961-1991. Filtered variables $F_{1}$ and $F_{2}$ obtained by eigen-vector filtering (EVF) for principal zooplanktonic species/genera and for total copepods. The species or genera are arranged according to the results of the classification of the trends, showed in table I. Note that scales are different.

showed an interannual cycle of 54 months (40\% of variance associated to this harmonic, table - 1 ). Temora and Acartia species had exceptional densities at the beginning and at the end of the time series (figure $3 g-h$ ), respectively. The annual periods of maximum abundance of these three taxa are indicated by the multi-year averages showed in figure $4 g-h$. The category 'total copepods', which does not include the species $C$. finmarchicus and $M$. lucens, show quite identical $F_{1}$ and $F_{2}$ (figure 3d).

Table II. Results of harmonic analysis on $F_{1}$ and $F_{2}$ of the principal copepods of the Gulf of Maine from May 1982 to April 1991 (* until December 1990 for Acartia). Significant harmonics and \% of variance associated within each $F_{1}$ and $F_{2}$ are indicated. $\propto$ indicates the $\propto$ period representing variability associated to the general trend of the series. Periodicities having maximum variance are in bold.

\begin{tabular}{|c|c|c|c|c|}
\hline & \multicolumn{2}{|c|}{$F_{1}$} & \multicolumn{2}{|r|}{$F_{2}$} \\
\hline & $\begin{array}{l}\text { Significant harmonics } \\
\text { (months) }\end{array}$ & $\%$ of associated variance & $\begin{array}{l}\text { Significant harmonics } \\
\text { (months) }\end{array}$ & $\%$ of associated variance \\
\hline Calanus finmarchicus & $\propto$ & 54 & 12 & 52 \\
\hline Metridia lucens & $\propto, 54$ & 36, 29 & $13.5, \mathbf{1 2}, 9.8$ & $16, \mathbf{3 4}, 13$ \\
\hline Oithona spp. & $\propto, 54,27$ & $\mathbf{4 0}, 26,14$ & 12 & 60 \\
\hline Temora longicornis & $\propto, 54$, 21.6, 18 & $16,15, \mathbf{2 3}, 18$ & $\mathbf{1 2}, 10.8,8.9$ & $25,17,18$ \\
\hline Acartia spp.* & $\propto, 54,20.8$ & $\mathbf{2 5}, 24,18$ & 11.6, $10.4,9.5$ & 29, 16,18 \\
\hline Pseudocalanus spp. & $\propto, \mathbf{5 4}, 12$ & $20, \mathbf{4 0}, 16$ & $12,7.2$ & 49, 14 \\
\hline Centropages typicus & 12 & 84 & $\propto, 54,12$ & $21,14, \mathbf{4 3}$ \\
\hline
\end{tabular}




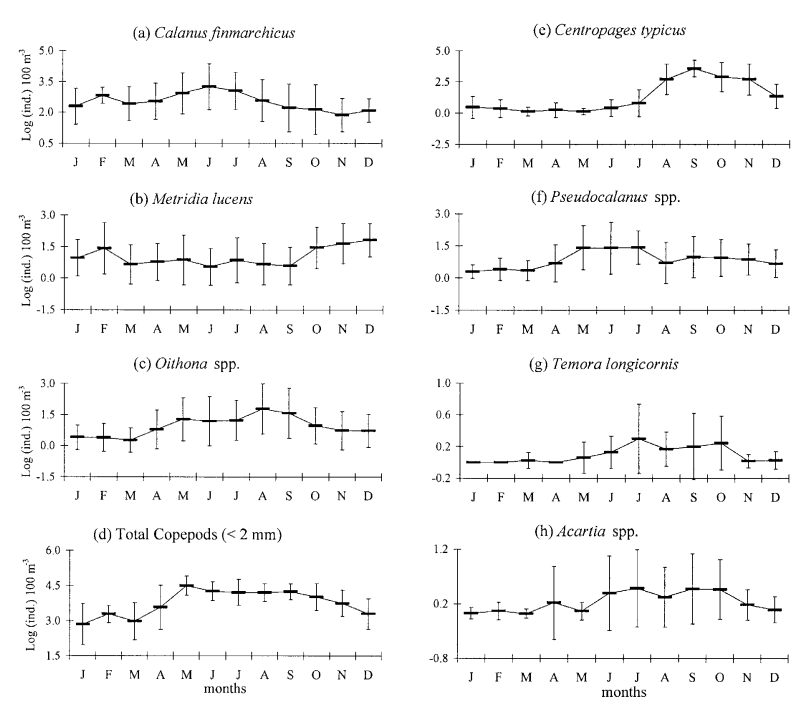

Figure 4. Gulf of Maine, 1961-1991. Thirty-year averages of each month $\left(\log _{10}\right.$ ind $\left.100 \mathrm{~m}^{-3}\right)$ and standard deviations of principal zooplanktonic species/genera and of total copepods. Note that scales are different.

The results of the classification of the principal trends are consistent with what is visible in the monthly abundance raw data $\left(\log _{10}\right.$ ind. $\left.100 \mathrm{~m}^{-3}\right)$ per year figure 5 ). For example, C. typicus (figure 5e) repeats the same pattern of high abundance over the period August-November and low abundance over the period March-May over time, without major changes from year to year. C. finmarchicus (figure 5d), on the other hand, shows an interannual variation, in addition to the seasonal variability, with lower densities in the first half of the series than in the second half (a linear, increasing trend already identified by Jossi and Goulet 1993, and further discussed by Conversi et al. 2001). Analogously, the increasing of $F_{1}$ of $M$. lucens corresponds to the increasing abundance of this species between 1980 and 1990 (fgure 5b). Within the interannual/seasonal taxa, Acartia spp. had two exceptional maxima of monthly abundance, at the end of the time series (fgure 5h).

Sea surface temperature (SST) in the Gulf of Maine followed a seasonal cycle with minimum of around $4{ }^{\circ} \mathrm{C}$ in February-March and maximum of $16-17^{\circ} \mathrm{C}$ in AugustSeptember. Harmonic analysis was performed on the interannual trend, $G_{t}$, extracted with the Census 2 method (figure 6), indicating a minor cycle of around 3-3.5 years and two major cycles of 15.5 and 30 years. $G_{t}$ showed a decreasing trend from 1961 to 1965 , an increasing trend from the mid-1960s to 1980, and a minor oscillation during the last 10 years of the series.

The interannual trend of SST, $G_{t}$ was compared to $F_{1}$ of the zooplanktonic species with a strong interannual variability (foure 7 ). A cross-correlation was performed between these filtered variables during the period January 1980-December 1991 (Goure \&). To distinguish the most important correlations between zooplankton and SST, only values with $P \leq 1 \%$ level were retained, although the variables represented filtered series. The results of this analysis (figure showed that a strong negative correlation exists between long-term variations of Calanus finmarchicus and sea surface temperature at a lag of about 0 months, meaning that low values of SST correspond to high abundances of the Calanus species. However, a positive correlation seems to be at a lag of 2.5 years, with temperature preceding $C$. finmarchicus, suggesting that the sign of correlation may change depending on the temporal scale investigated. At the same lag, Oithona spp. seems to show instead a significant negative correlation with SST, meaning that higher temperature proceeds 2.5 years lower densities of this copepod. High abundances of both Oithona spp. and Metridia lucens seem to precede by 2.5 years high values of SST (see positive correlation at lag of 30 months). Such correlations are meaningless.

\section{DISCUSSION}

A major problem with biological decadal time series is that often, for economical or logistic constraints, there are suspensions in the program, which result in gaps in the time series. Several statistical analyses require series without gaps, and therefore several methods have been devised (e.g. splines functions: Lancaster and Salkauskas, 1986; area interpolation: Fox and Brown, 1965. principal component analysis: Inلliffe, 1986) to predict the missing data. However, the original information is modified by the insertion of simulated data. The CPR time series in the Gulf of Maine is a particularly difficult case because it contains a large gap (35 consecutive months) that prevents the simulation of missing data. Because of this, all previous studies have used annually averaged data Lossi and Goulet, 1993; Conversi et al 2001) thus loosing the monthly information. With this work, we have used a different approach, that of extracting statistically reproducible trends while retaining the missing data, utilizing the EVF method. This way we 
(a) Calanus finmarchicus

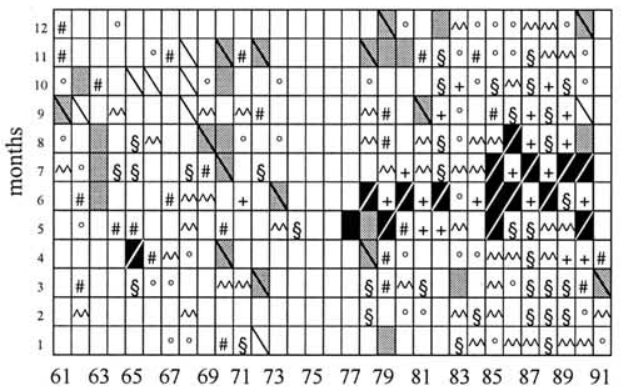

(c) Oithona spp.

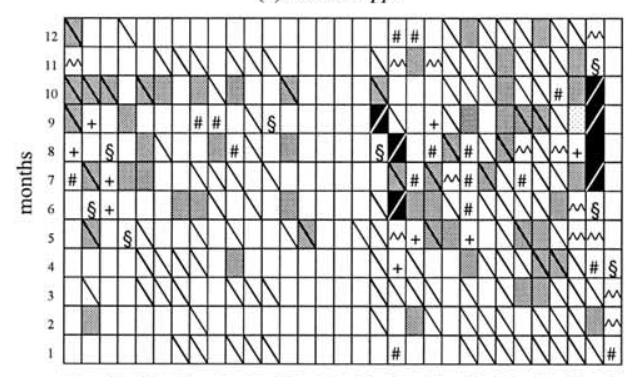

$\begin{array}{llllllllllllllll}61 & 63 & 65 & 67 & 69 & 71 & 73 & 75 & 77 & 79 & 81 & 83 & 85 & 87 & 89 & 91\end{array}$

(e) Centropages typicus

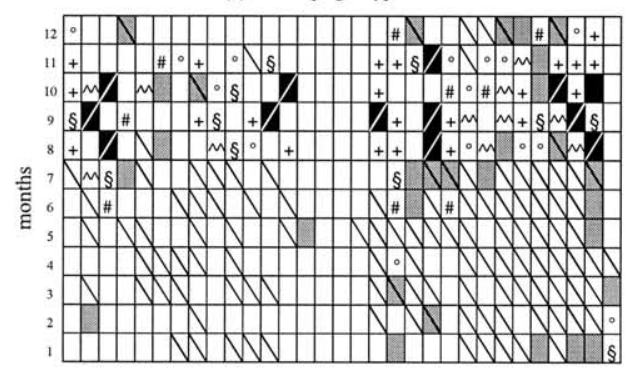

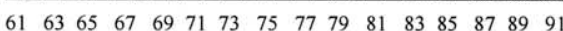

(g) Temora longicornis

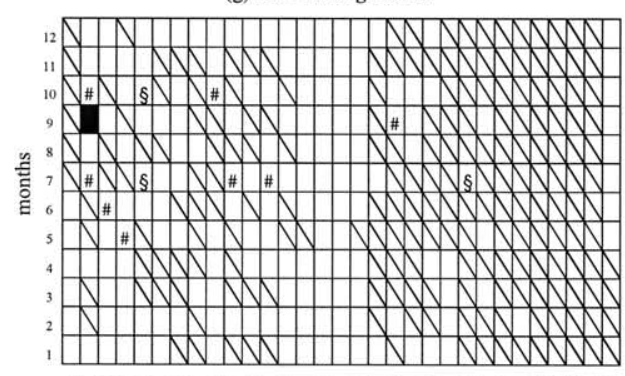

$\begin{array}{llllllllllllllll}61 & 63 & 65 & 67 & 69 & 71 & 73 & 75 & 77 & 79 & 81 & 83 & 85 & 87 & 89 & 91\end{array}$

Years (b) Metridia lucens

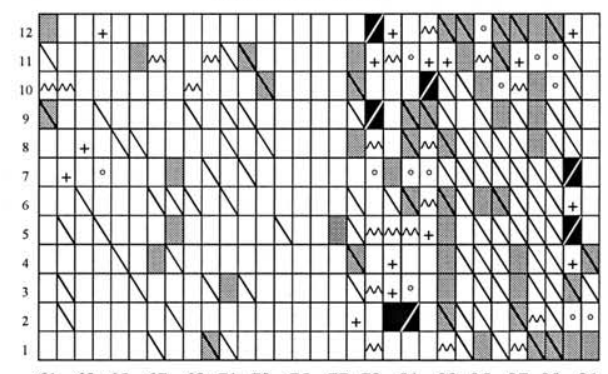

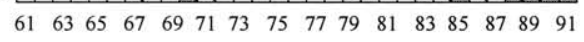

(d) Total Copepods

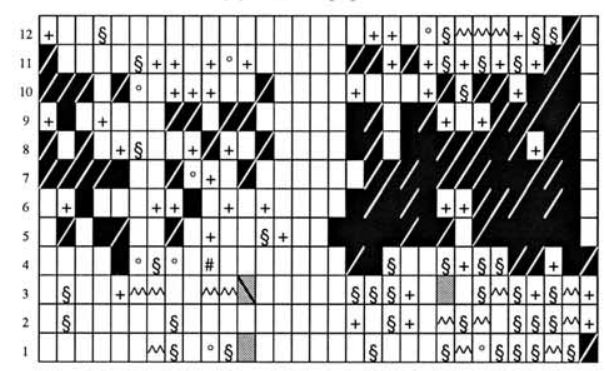

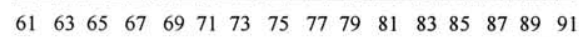

(f) Pseudocalanus spp.

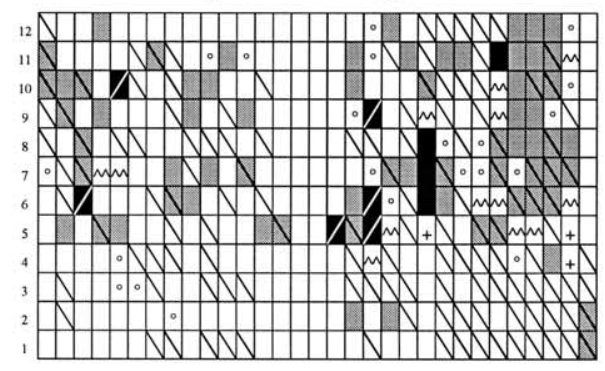

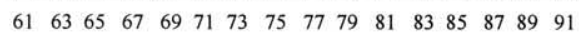

(h) Acartia clausi

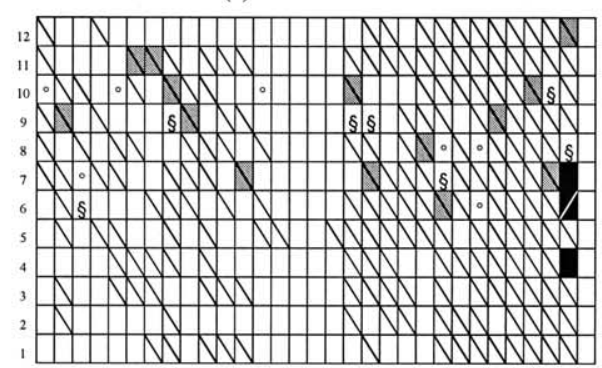

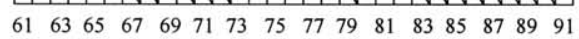

Years

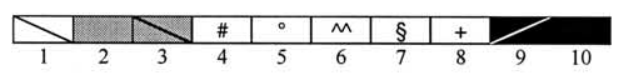

Figure 5. Gulf of Maine, 1961-1991. Monthly densities $\left(\log _{10}\right.$ ind $\left.100 \mathrm{~m}^{-3}\right)$ per year of the principal zooplanktonic species/genera and of total copepods. The values are expressed as classes of abundance, which are detailed as follows : 1 : $0-0.5 ; 2: 0.5-1 ; 3: 1-1.5 ; 4: 1.5-2 ; 5: 2-2.5 ; 6: 2.5-3$; 7: $3-3.5 ; 8: 3.5-4 ; 9: 4-4.5 ; 10: 4.5-5.5$. 


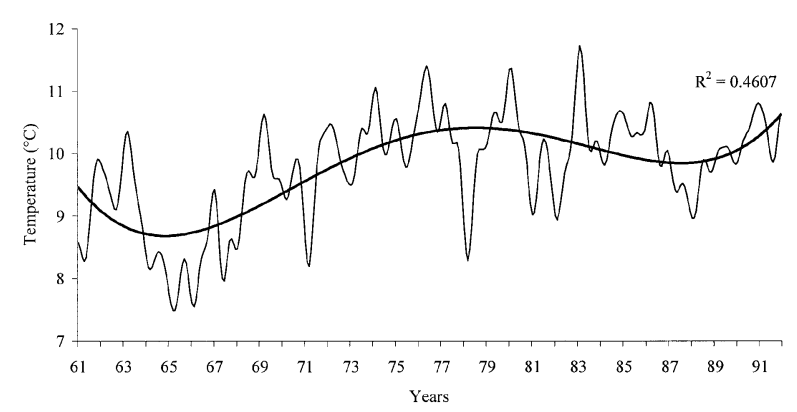

Figure 6. Gulf of Maine, 1961-1991. Interannual trend $G_{t}$ for the SST obtained by Census 2 method. Fourth-order polynomial fit is superimposed and the correlation coefficient $R^{2}$ indicated.
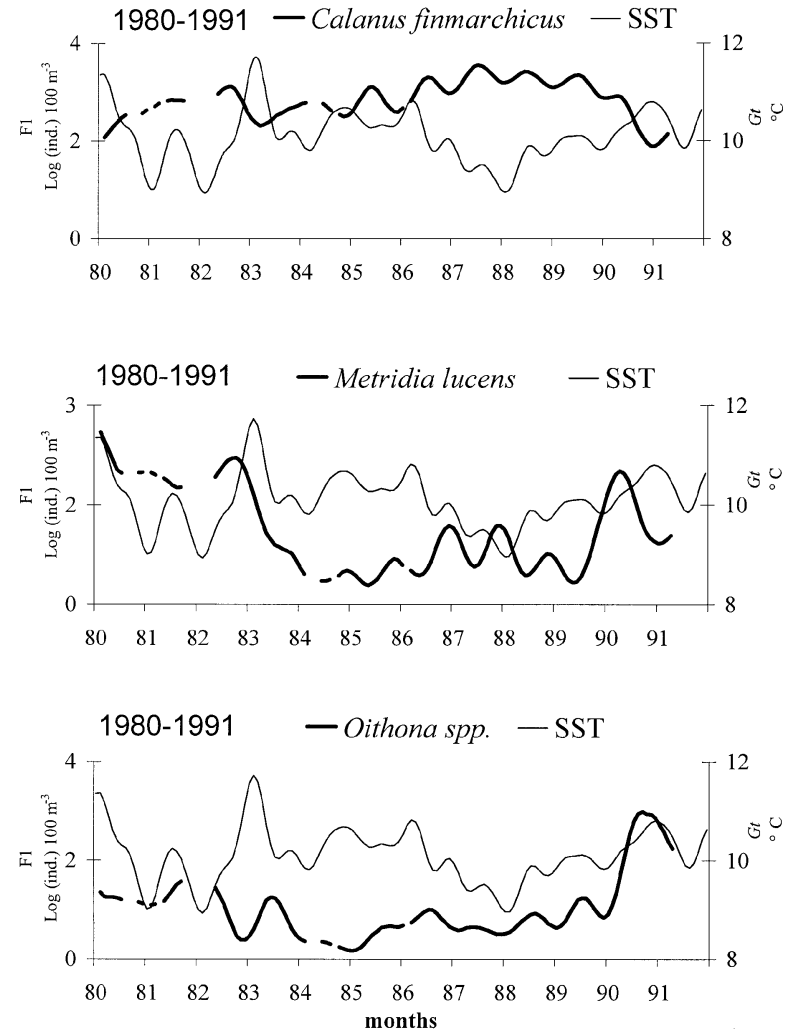

Figure 7. Gulf of Maine, 1980-1991. Interannual trend for the SST, $G_{t}$, compared with interannual trends $F_{1}$ of the principal zooplanktonic species or genera, which showed the greater variations at a long time scale. Note the scales are different.

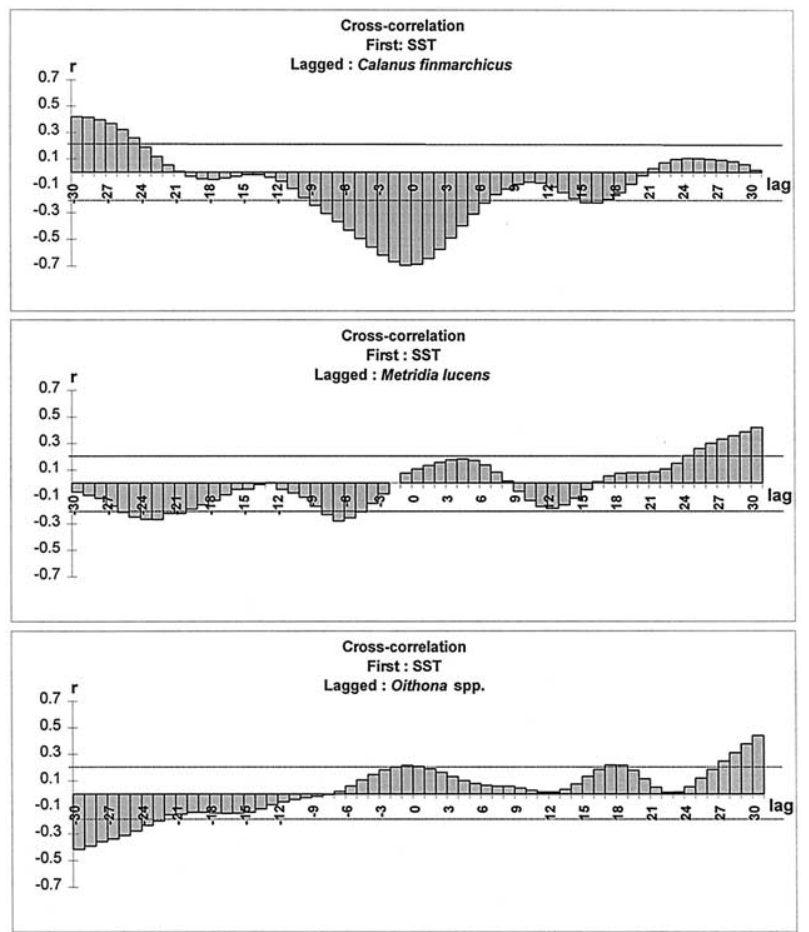

Figure 8. Gulf of Maine, 1980-1991. Cross-correlation function between the interannual trend of SST $\left(G_{t}\right)$ and the interannual trend $\left(F_{1}\right)$ of the most interannual zooplanktonic taxa. Straight lines indicate the $99 \%$ confidence interval.

have been able to use the full information contained in the monthly sampling without resorting to annually averaged data.

The trends $F_{1}$ and $F_{2}$ extracted with the EVF represent the major modes of variability of the zooplanktonic species under study, which are the interannual and annual variability, as shown by harmonic analysis of the $F_{i}$ (table -1 ) and comparisons of such patterns between taxa and environmental variables can be made.

The taxa studied here are the numerically dominant zooplankton species in the Gulf of Maine. Thus, changes in their abundance can have far-ranging consequences in the trophic chain. The Gulf of Maine area, together with the Gulf of St. Lawrence, seems to be a source of Calanus finmarchicus Meise and O'Reilly 1996: Buckin and Kocher, 1996) for the highly productive Georges bank area, an area which has been selected as a GLOBEC study area for its importance and strategic location (Wiebe et al, 2001). 
EVF allows the classification of zooplanktonic species according to their main type of variability, indicating Calanus finmarchicus, Metridia lucens and Oithona spp. as 'interannually dominated' taxa, Centropages typicus as 'seasonally dominated' taxa and Pseudocalanus spp., Temora longicornis, Acartia spp. as intermediate between the two. This classification can be helpful to identify species whose major variance mode is interannual which are potential indicators of environmental and in particular climatic variations.

This classification is consistent with what is shown by the raw data (figure 5 ), and for some species such as $C$. finmarchicus, with the finding of other authors in the same area (Jossi_and Goulet, 1993). On the other hand, the interannual variation of Oithona spp. and Metridia lucens shown by our analyses (Ggure 3b, d; table - could not be detected by the linear method used by Iossiand Goulet (1993). Anyway, the decline in abundance of $M$. lucens after 1983, was indicated by Sherman et al.(1998) from MARMAP data series.

The species whose variance is mostly in the interannual range (Calanus finmarchicus, Metridia lucens and $\mathrm{Oi}$ thona spp.) are of special interest because they may be particularly sensitive to environmental and climatic changes. One of these species, $C$. finmarchicus, is a major species in the whole northern Atlantic as well as a GLOBEC target species. The results (Ggure 8 ) of a preliminary comparison with an environmental variable, SST, indicate that for these three species, and in particular for $C$. finmarchicus, temperature can be an important factor, and can possibly be used for prediction. The high values at the edge of the cross-correlation chosen interval (figure 8) may indicate that the scale of the interannual relationship is longer than what we can detect with the given data. The relationship between species and temperature can be different at different temporal scales (as in the case of $C$. finmarchicus). Calanus finmarchicus shows a strong negative correlation with SST at about lag 0 month, which suggests that in this area, which is on the southern fringe of $C$. finmarchicus' distribution, a small change in the SST may have immediate effects (of opposite sign) on its abundance. Other authors already indicated Calanus as a cold water species, in this same area (Meise and O'Reilly, 1996) and in the North Sea Eromentin and Planque, 1996: Reid et al. 1998) but they also pointed out that this correlation is more likely due to the area hydrography than to a direct temperature effect. On the other hand, on a longer temporal scale (30 months or 2.5 years), there seems to be a positive correlation, although it is difficult to define as we are at the limit of the series. This would be consistent with the findings by Conversi et al. (2001) who, using CPR data annually averaged, find a significant, positive relationship between Calanus finmarchicus and SST in the Gulf of Maine, with temperature preceding $C$. finmarchicus variations by about 2 years. It is likely that correlations at 0 lag indicate short-term links (direct or quasi-direct effects) with the temperature, while lagged correlations beyond the year may indicate (as Conversi et al, 2001 suggest) a change in the water column structure of advective type and possibly of climatic origin.

Oithona spp. shows at the same time scale ( 2.5 years) a negative correlation with SST. This fact may suggest a switch from small to larger copepods over time, but such a hypothesis needs to be investigated with additional species composition data before it can be supported.

\section{Acknowledgements}

We are grateful to our colleagues from the Northeast Fisheries Science Center, NOAA, Narragansett, RI, and particularly to Ken Sherman, for his helpful support. This work has been supported by NSF grant \# OCE 9632841. This is contribution 210 of the US GLOBEC Program, jointly funded by NSF and NOAA. This work is part of the French programme PNEC (Programme National Environnement Côtier), art.4, thème: 'Influence des facteurs hydroclimatiques ou anthropiques sur la variabilité spatio-temporelle des populations et écosystèmes marins'. 
Appendix 1.

Simplified scheme of the different steps of the EVF method. $\mathrm{X}_{t}$ : initial series; $\mathrm{X}_{i}$ : $i$ th predicted matrix; $C i$ : $i$ th principal component; $U_{i}$ : ith eigenvector.

1) Example: Time series of Venus ovata (Pierre Noire)

$$
\mathrm{xt}_{\mathrm{t}}=\left(\begin{array}{c}
1 \\
2 \\
\cdot \\
\cdot \\
\cdot \\
6
\end{array}\right)
$$

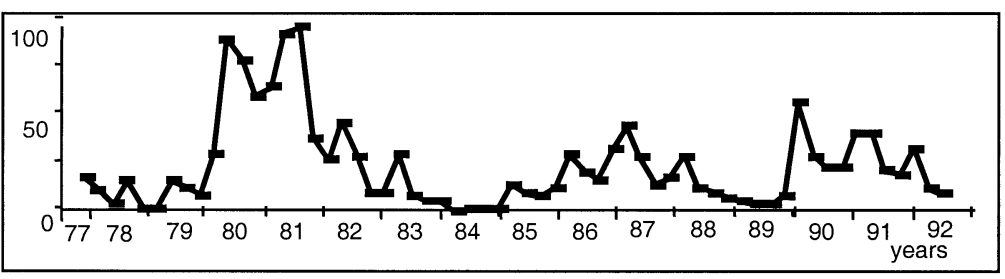

Autocorrelation function of $x_{\underline{t}}$

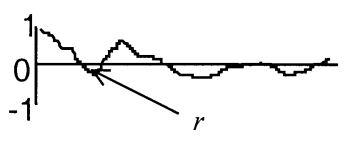

Series $x_{t}$ shifted $r$ times
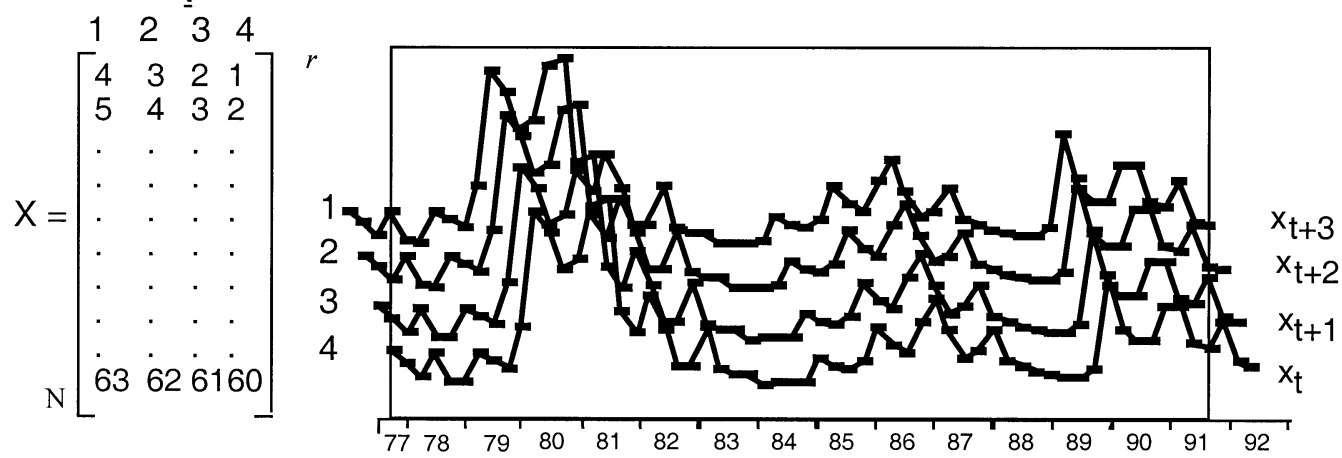

2) Autocovariance matrix and PCA

$$
\text { Covariance }=\left[\begin{array}{cccc}
C_{11} & C_{12} & \cdot & C_{14} \\
C_{21} & C_{22} & \cdot & C_{24} \\
\cdot & \cdot & \cdot & \cdot \\
C_{41} & C_{42} & \cdot & C_{44}
\end{array}\right] \stackrel{\text { P.C. } A}{\longrightarrow} \quad \hat{x}_{i}=C_{i} \cdot U_{i}^{\prime}
$$

3) Estimation of filtered variables Fi from components and egenvectors

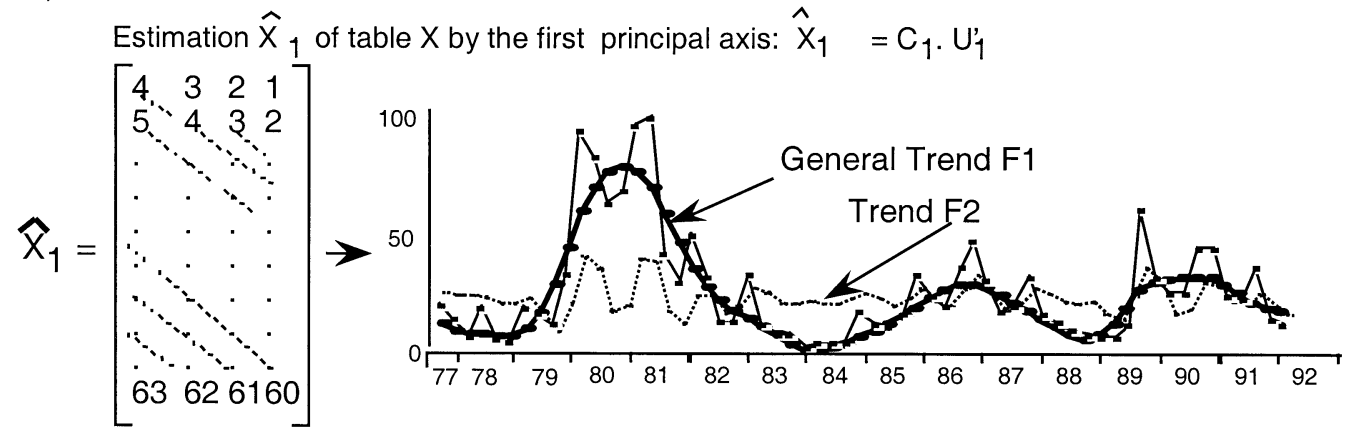




\section{Appendix 2.}

Numerical procedure utilized for calculating filtered series $F_{i}$ with EVF method.

Ibanez and Etienne(1992) showed that the filtered series $F_{i}$, corresponding to the principal axis $f_{i}$, may be calculated by a weighted moving average (WMA) on the original data set. With the $r$ shifted series, WMA is of order $r-1$ and has $2(r-1)+1$ terms. For the principal axis $f_{i}, j$ being the term of the WMA, the $j$ th weight $P_{j f}$ is a linear combination of the elements of corresponding eigenvector, $U_{i k}$ :

$$
P_{j, f}=\sum_{k=1}^{m-|j|+1} U_{k, f} U_{k+|j|, f}
$$

with $m=r-1,-m<j<+m$ and $U_{k, f}$ the $k$ th element of eigenvector $f$.

$x_{t}$ being the original series (with $t=1, \ldots, N$ ), the smoothed variable $F_{t, f}$, corresponding to the eigenvector $f$ at point $t$ is calculated as follows:

- When $m<t<(N-m+1)$

$$
F_{t, f}=\sum_{\substack{k=m \\ 1>k+k<n}}^{m} P_{k, f} x_{t+k} /(m+1)
$$

- When $t<m+1$

$$
\begin{gathered}
F_{t, f}=\sum_{k=-t+1}^{m-1}\left(P_{k, f} \sum_{l=1}^{m-t+1} U_{l, f} U_{l-k, f}\right) x_{t+k, f}+ \\
\sum_{k=m-t+1}^{m} P_{k, f} x_{t+k}
\end{gathered}
$$

- When $t>(N-m)$

$$
\begin{gathered}
F_{t, f}=\sum_{k=N-t-m+1}^{N-t}\left(P_{k, f} \sum_{l=N-t+2}^{m+1} U_{l, f} U_{l-k, f}\right) x_{t+k, f}+ \\
\sum_{k=-m}^{N-t-m} P_{k, f} x_{t+k}
\end{gathered}
$$

The weights of the MAW allow to compute the gain function associated to each filtering thus to know which frequency bands have been eliminated. The gain function may justify a posteriori the choice of $r$.

\section{REFERENCES}

Anderson, T.W., 1971. The Statistical Analysis of Time Series. John Wiley \& Sons, New York.

Béthoux, N., Étienne, M., Ibanez, F., Rapaire, J.L., 1980. Spécificités hydrologiques des zones littorales. Analyses chronologiques par la méthode Census II et estimation des échanges océan-atmosphère appliquées à la baie de Villefranche-sur-mer. Ann. Inst. Océanogr. $56,81-95$.

Bigelow, H.B., 1926. Plankton of the offshore waters of the Gulf of Maine. Bull. U.S. Bur. Fish. 40, 1-509.

Bigelow, H.B., 1927. Physical oceanography of the offshore waters of the Gulf of Maine. Bull. U.S. Bur. Fish. 40, 511-1027.

Bucklin, A., Kocher, T.D., 1996. Source regions for recruitment of Calanus finmarchicus to Georges Bank: Evidence from molecular population genetic analysis of mtDNA. Deep-Sea Res. 43, $1665-1681$.

Bumpus, D.F., Lauzier, L., 1965. Surface circulation on the continental shelf off Eastern North America between Newfoundland and Florida. Serial Atlas of the Marine Environment. Folio F. Am. Geogr. Soc.

Colebrook, J.M., 1975. The continuous plankton recorder survey: automatic data processing method. Bull. Mar. Ecol. 8, 123-142.

Colebrook, J.M., 1978. Continuous plankton records: zooplankton and environment, North-East Atlantic and North Sea, 1948-1975. Oceanol. Acta 1, 9-23.

Conversi, A., Piontkovski, S., Hameed, S., 2001. Seasonal and interannual dynamics of Calanus finmarchicus in the Gulf of Maine (Northeastern US shelf) with reference to the North Atlantic Oscillation. Deep-Sea Res. in press.

Fox, W.T., Brown, J.A., 1965. The use of time-trend analysis for environmental interpretation of limestones. J. Geol. 73, 510-518.

Fromentin, J.M., Ibanez, F., 1994. Year-to-year changes in meteorological features of the French coast area during the last half-century. Examples of two biological responses. Oceanol. Acta 17, 285-296.

Fromentin, J.M., Planque, B., 1996. Calanus and environment in the eastern North Atlantic. II. Influence of the North Atlantic Oscillation on C. finmarchicus and C. helgolandicus. Mar. Ecol. Prog. Ser. 134, 111-118.

Hardy, A.C., 1939. Ecological investigations with the Continuous Plankton Recorder: Object, plan, and methods. Hull Bull. Mar. Ecol. 1, 1-57.

Ibanez, F., 1991. Treatment of the data deriving from the COST 647 project on coastal benthic ecology: The within-site analysis. In: Keegan, B. (Ed.), Space and Time Series Data Analysis in Coastal Benthic Ecology. Commission of the European Communities, pp. 5-41.

Ibanez, F., Dauvin, J.C., 1988. Long-term changes (1977 to 1987) in a muddy fine sand Abra alba-Melinna palmata community from the Western English Channel: multivariate time-series analysis. Mar. Ecol. Prog. Ser. 49, 65-81.

Ibanez, F., Etienne, M., 1992. Le filtrage des séries chronologiques par l'analyse en composantes principales de processus (ACPP). J. Rech. Océanogr. 16, 27-33. 
Ibanez, F., Etienne, M., 1998. PASSTEC: Programme d'analyse des séries spatio-temporelles en écologie côtière. Observatoire Océanologique de Villefranche-sur-Mer.

Ibanez, F., Dauvin, J.C., Etienne, M., 1993. Comparaison des évolutions à long terme (1977-1990) de deux peuplements macrobenthique de la baie de Morlaix (Manche occidentale) : relations avec les facteurs hydroclimatiques. J. Exp. Mar. Biol. Ecol. 169, 181-214.

Institut National de Statistique, 1965. Décomposition des séries chronologiques en leurs composantes suivant diverses méthodes. Études statistiques et économétriques. Bull. Stat., INS 10, 1449-1524.

Jolliffe, I.T., 1986. Principal Component Analysis. Springer-Verlag, Berlin.

Jossi, J.W., Goulet, J.R., 1993. Zooplankton trends: US north-east shelf ecosystem and adjacent regions differ from north-east Atlantic and North Sea. ICES J. Mar. Sci. 50, 303-313.

Kendall, M., 1976. Time-Series. Charles Griffin and Co., London.

Lancaster, P., Salkauskas, K., 1986. Curve and Surface Fitting. Academic Press, England.

Legendre, P., Legendre, L., 1998. Numerical Ecology, Developments in Environmental Modelling, vol. 20. Elsevier Science B.V., Amsterdam.

Meise, C.J., O'Reilly, J.E., 1996. Spatial and seasonal patterns in abundance and age-composition of Calanus finmarchicus in the Gulf of Maine and on Georges Bank: 1977-1987. Deep-Sea Res. II 43, 1473-1501.

Reid, P.C., Planque, B., Edwards, M., 1998. Is observed variability in the long-term results of the Continuous Plankton Recorder survey a response to climate changes? Fish. Oceanogr. 7, 282-288.

Sherman, K., 1980. MARMAP, a fisheries ecosystem study in the Northwest Atlantic Fluctuations in ichthyoplankton-zooplankton components and their potential for impact on the system. In: Diemer, F.P., Verberg, F.J., Mirkes, D.Z. (Eds.), Advanced Concepts in Ocean Measurements for Marine Biology. University of South Carolina Press, Columbia, South Carolina, pp. 3-37.
Sherman, K., Smith, W.G., Green, J.R., Cohen, E.B., Berman, M.S., Marti, K.A., Goulet, J.R., 1987. Zooplankton production and the fisheries of the northeastern shelf. In: Backus, R.H. (Ed.), Georges Bank. MIT Press, Cambridge, pp. 268-282.

Sherman, K., Grosslein, M., Mountain, D., Busch, D., O’Reilly, J.E., Theroux, R., 1988. The continental shelf ecosystem off the northeast coast of the United States. In: Postma, H., Zijlstra, J.J. (Eds.), Ecosystem of the World - 27 - Continental Shelves. Elsevier Science B.V., Amsterdam, pp. 279-337.

Sherman, K., Solow, A., Jossi, J., Kane, J., 1998. Biodiversity and abundance of the zooplankton of the Northeast Shelf ecosystem. ICES J. Mar. Sci. 55, 730-738.

Shiskin, J., Eisenpress, H., 1957. Seasonal adjustment by electronic computer methods. J. Am. Stat. Assoc. 52, 415-449.

Souprayen, J., Dauvin, J.C., Ibanez, F., Lopez-Jamar, E., O'Connor, B., Pearson, T.H., 1991. Long-term trends of subtidal macrobenthic communities: numerical analysis of four north-western European sites. In: Keegan, B. (Ed.), Space and Time Series Data Analysis in Coastal Benthic Ecology. Commission of the European Communities, pp. 65-438.

Takens, F., 1981. Detecting strange attractors in turbulence. In: Rand, D.A., Young, L.S. (Eds.), Dynamical Systems and Turbulence. Springer-Verlag, New York, pp. 366-381.

Townsend, D.W., Christensen, J.P., Stevenson, D.K., Graham, J.J., Chenoweth, S.B., 1987. The importance of a plume of tidallymixed water to the biological oceanography of the Gulf of Maine. J. Mar. Res. 45, 699-728.

Warner, A.J., Hays, G.C., 1994. Sampling by the Continuous Plankton Recorder survey. Prog. Oceanogr. 34, 237-256.

Wiebe, P.H., Beardsley, R.C., Bucklin, A., Mountain, D.G., 2001. Coupled biological and physical studies of plankton populations in the George Banks region and related North Atlantic GLOBEC study sites. Deep Sea Res. 48, 1-2. 